\title{
Association of socioeconomic position with maternal pregnancy and infant health outcomes in birth cohort studies from Brazil and the UK
}

\author{
A Matijasevich, ${ }^{1}$ C G Victora, ${ }^{1}$ D A Lawlor, ${ }^{2}$ J Golding, ${ }^{3}$ A M B Menezes, ${ }^{1}$ \\ C L Araújo, ${ }^{1}$ A J D Barros, ${ }^{1}$ I S Santos, ${ }^{1}$ F C Barros, ${ }^{4}$ G Davey Smith ${ }^{2}$
}

- Additional materials are published online only. To view these files please visit the journal online (http://jech.bmj. com/content/66/2.toc).

${ }^{1}$ Post Graduate Programme in Epidemiology, Federal University of Pelotas, RS, Brazil ${ }^{2}$ MRC Centre for Causal Analyses in Translationa Epidemiology, Department of Social Medicine, University of Bristol, Bristol, UK

${ }^{3}$ Department of Community Based Medicine, University of Bristol, Bristol, UK

${ }^{4}$ Postgraduate Programme in Health and Behavior, Catholic University of Pelotas, Pelotas, Brazil

\section{Correspondence to}

Alicia Matijasevich, Rua

Marechal Deodoro, 1160-3rd floor, CEP 96020-220, Pelotas, RS, Brazil;

amatija@yahoo.com

Accepted 6 April 2010 Published Online First 13 July 2010

\section{(2) UNLOCK:}

This paper is freely available online under the BMJ Journals unlocked scheme, see http:// jech.bmi.com/site/about/ unlocked.xhtml

\begin{abstract}
Background Socioeconomic inequalities in health outcomes are dynamic and vary over time. Differences between countries can provide useful insights into the causes of health inequalities. The study aims to compare the associations between two measures of socioeconomic position (SEP) - maternal education and family income-and maternal and infant health outcomes between ALSPAC and Pelotas cohorts.

Methods Birth cohort studies were started in Avon, UK, in 1991 (ALSPAC) and in the city of Pelotas, Brazil, in 1982, 1993 and 2004. Maternal outcomes included smoking during pregnancy, caesarean section and delivery not attended by a doctor. Infant outcomes were preterm birth, intra-uterine growth restriction (IUGR) and breast feeding for $<3$ months. The relative index of inequality was used for each measure of SEP so that results were comparable between cohorts.
\end{abstract}

Results An inverse association (higher prevalence among the poorest and less educated) was observed for almost all outcomes, with the exception of caesarean sections where a positive association was found. Stronger incomerelated inequalities for smoking and education-related inequalities for breast feeding were found in the ALSPAC study. However, greater inequalities in caesarean section and education-related inequalities in preterm birth were observed in the Pelotas cohorts.

Conclusions Mothers and infants have more adverse health outcomes if they are from poorer and less welleducated socioeconomic backgrounds in both Brazil and the UK. However, our findings demonstrate the dynamic nature of the association between SEP and health outcomes. Examining differential socioeconomic patterning of maternal and infant health outcomes might help understanding of mechanisms underlying such inequalities.

\section{INTRODUCTION}

Socioeconomic position (SEP) refers to the social and economic factors that influence a person's status within the structure of a society. ${ }^{1}$ Education and income are frequently used as generic indicators of SEP. However, while education is thought to capture knowledge-related assets of an individual, income is the indicator that most directly measures the material resources component. ${ }^{12}$

SEP indicators have been related to a range of adult health outcomes, including morbidity, ${ }^{34}$ poor self-rated health ${ }^{5}$ and mortality. ${ }^{6}$ SEP indicators are associated with health at different stages in the life course via a number of, possibly interacting, mechanisms. Even though socioeconomic disadvantage is often related to poorer health, this general tendency hides important heterogeneity. ${ }^{8}$

Pregnancy and early childhood are particularly vulnerable periods of time at which adverse socioeconomic circumstances have long lasting effects. Some of the most consistent findings in public health research are the large SEP disparities in pregnancy outcomes such as intrauterine growth restriction (IUGR) and preterm birth. IUGR and preterm birth are considered key outcomes due to their strong association with infant mortality, longterm morbidity and high healthcare cost. ${ }^{9}$

Inequalities in health outcomes are frequently consequence of inequalities among factors that determine health outcomes. Smoking during pregnancy and nutrition play an important role in relation to health inequalities in pregnancy and early childhood. The marked social gradient in smoking during pregnancy is a major determinant of impaired fetal growth and the social gradient in breast feeding contributes to higher rates of illness in childhood among children from low-income families. ${ }^{10}$ The relation between specific SEP indicators and specific health outcomes can vary between countries due to differences in the cultural contexts of the SEP indicators. Such differences can provide useful insights into the causes of health inequalities.

In the present study we examine the associations of two measures of SEP-maternal education and family income-with maternal and infant health outcomes in a birth cohort study from a high-income country (the Avon Longitudinal Study of Parents and Children, ALSPAC, in Britain) and in three birth cohorts from a middle-income country (the Pelotas 1982, 1993 and 2004, in Brazil). These studies were chosen to reflect populations with different levels of wealth and of socioeconomic inequalities as well as their similarity in variable definitions and the availability of comparable questions. Our aim is to compare the relative magnitudes of these associations between the ALSPAC and Pelotas birth cohorts as well to study trends of those associations across the Pelotas studies.

\section{METHODS}

\section{Research setting and study design}

The ALSPAC study started during pregnancy and aimed to enroll all women who were resident in the three Bristol-based health districts of the county of Avon and who had an expected date of delivery between 1 April 1991 and 31 December 1992.11 
A total of 14541 pregnant women (approximately 85\% of those eligible) were recruited and 13678 had a live born, singleton child. Information was obtained both from self-completion questionnaires and from clinical records. ${ }^{11} 12$

During the years of 1982, 1993 and 2004, birth cohort studies representing all births to mothers residing in the urban area of the city of Pelotas, Brazil, were carried out through primary data collection and using much of the same methodology. ${ }^{13-15}$ The present paper uses perinatal data obtained soon after delivery and data from 12-month follow-up. With the exception of the 2004 cohort, where the whole cohort was studied at the 12month follow-up (3907 individuals), ${ }^{13}$ a systematic sample of each birth cohort was followed-up at 12 months in 1982 and 1993 (1457 and 1364 individuals, respectively). ${ }^{14} 15$ The analyses were restricted to live births, because several indicators (eg, IUGR or preterm birth) do not include stillbirths. The same variable definitions and comparable questions were used in the ALSPAC and Pelotas birth cohort studies.

\section{Outcome and covariates}

Smoking habits during pregnancy were based on maternal selfassessment and those women who smoked at least one cigarette per day in any trimester of pregnancy were classified as 'ever smoked during pregnancy'.

Delivery not attended by a doctor was defined as when the newborn was delivered by a midwife, medical student, a student midwife or another person not specified as a doctor and where there was no indication that a doctor had been present. Home births represented less than $1 \%$ of all births in the four cohorts and were included in the analyses if data were available. Information about method of delivery (vaginal or caesarean section) was extracted from maternal hospital records in the ALSPAC study and informed by women in the perinatal interview in the Pelotas cohort studies.

Preterm birth was defined as birth that occurred before 37 complete weeks of gestation. Gestational age was recorded using last menstrual period (LMP) in the 1982 Pelotas cohort study and cases with implausible birthweight-gestational age combinations ${ }^{16}$ were considered missing data. In the 1993 and 2004 Pelotas cohorts, as well in the ALSPAC study, gestational age was estimated based on the LMP. If the LMP date was considered unreliable or unknown, then the paediatric/obstetric assessment of the newborn was used.

IUGR was defined as birth weight $<10$ th percentile for gestational age and gender according to the reference curve developed by Kramer et al ${ }^{17}$

Any type of breast feeding (exclusive, partial or complementary breast feeding) was used to create the variable breast feeding for less than 3 months; those who never breast fed were included in this category. information was collected at the age of 12 months and, therefore, was not assessed for children who died in the first year of life.

The following variables were considered as potential confounders or mediators in the association between SEPs and maternal and infant outcomes: mothers' ethnic origin (white and black/mixed ethnic origin), maternal age ( $<20,20-34$ and $\geq 35 \mathrm{y}$ ), marital status, parity $(0,1,2+)$, pre-pregnancy body mass index $\left(<18.5,18.5-<25,25-<30 \text { and } \geq 30 \mathrm{~kg} / \mathrm{m}^{2}\right)^{18}$ and information on urinary tract infection, hypertension (pre-eclampsia or eclampsia) and hospital admission during pregnancy.

\section{Measures of socioeconomic position}

Two SEP indicators were used: family income and maternal education. In the Pelotas cohort studies, family income of the month prior to delivery was collected in the perinatal interview. In the ALSPAC study, family income per week was collected at 33 months after delivery. Because of the different currencies used in ALSPAC and Pelotas studies, quintiles of family income were calculated in each study.

In the Pelotas cohort studies, maternal schooling at the time of delivery was collected as a continuous variable and categorised in 0-4, 5-8, 9-11 and $\geq 12$ completed years of formal education. Education levels used in England are not based on the number of years of schooling, because the highest level of education can be obtained after school. In the ALSPAC study, maternal education was collected at 32 weeks of pregnancy as a grouped variable according to increasing levels of achievement: CSE (certificate of secondary education-subject-specific qualifications of a lower level than O-levels that were generally obtained at age $16 \mathrm{y}$ (the minimal school leaving age from 1974 in England))/none, vocational, O-level (ordinary-level-subject-specific qualifications generally obtained at age $16 \mathrm{y}$ ) and A-level (advancedlevel-subject-specific qualifications generally obtained at age $18 \mathrm{y}$ and required for university entry)/university degree.

\section{Indices of inequality}

For each measure of SEP, a relative index of inequality (RII) was derived. ${ }^{19}$ This takes account of differences in the proportion of participants in each category for the different measures and between the four cohorts. Results are interpreted as a comparison of the extremes - those at the bottom with those at the top of the income or educational hierarchy. The larger the RII the greater the degree of inequality across the socioeconomic hierarchy.

\section{Data analysis}

We used $\chi^{2}$ tests to compare the distribution of maternal characteristics between ALSPAC and Pelotas studies. Whenever possible, $\chi^{2}$ tests of trend were used to compare the distribution of maternal characteristics between the three Pelotas cohort studies.

Multiple logistic regression analyses were used to assess the associations of the socioeconomic and educational indices of inequality with each of the maternal and infant health outcomes for each cohort separately. Variables were introduced in the adjusted analysis in sequential steps. In the final model of each outcome we further adjusted for the other SEP indicator to determine the independent contributions of maternal education and family income.

The proportion of missing values for family income in the ALSPAC database was $37 \%$ so we used multivariate multiple imputation analysis to assess the impact of missing values on the adjusted estimates. ${ }^{20}$ All the analyses were repeated with no imputation for missing values and these results are given as online supplementary material.

All analyses were performed with Stata V.11.0.

\section{RESULTS}

The core ALSPAC study consisted of 14541 pregnancies and, after excluding stillbirths, abortions and multiple births, there remained 13678 women for analysis. The 1982, 1993 and 2004 Pelotas cohort studies consisted of 6011, 5304 and 4287 births and, after excluding stillbirths and multiple births, there remained 5816, 5168 and 4147 women in each cohort for analysis, respectively.

Marked differences in maternal and infant's characteristics were observed between the four cohort studies (table 1). The Pelotas cohort studies had higher frequencies of women of black/ mixed ethnic origin, with extremes in ages, single mothers and 
Table 1 Maternal and infant's characteristics in the ALSPAC and Pelotas birth cohort studies

\begin{tabular}{|c|c|c|c|c|c|c|}
\hline Variables & $\begin{array}{l}\text { ALSPAC 1991/92 } \\
\text { n (\%) }\end{array}$ & $\begin{array}{l}\text { Pelotas } 1982 \\
\text { n (\%) }\end{array}$ & $\begin{array}{l}\text { Pelotas } 1993 \\
\text { n (\%) }\end{array}$ & $\begin{array}{l}\text { Pelotas } 2004 \\
\text { n (\%) }\end{array}$ & $\mathbf{p}^{*}$ & $\mathbf{p} \dagger$ \\
\hline \multicolumn{7}{|l|}{ Ethnic origin } \\
\hline White & $11737(97.4)$ & $4773(82.1)$ & $3996(77.3)$ & $3030(73.1)$ & $<0.001$ & $<0.001$ \\
\hline \multicolumn{7}{|c|}{ Family income (quintils) } \\
\hline 1st (poorest) & $1727(20.0)$ & $1159(19.9)$ & $1037(20.1)$ & $846(20.4)$ & 0.001 & - \\
\hline 4th & $1726(20.0)$ & $1162(20.0)$ & $1029(19.9)$ & $846(20.4)$ & & \\
\hline 5th (better-off) & $1726(20.0)$ & $1163(20.0)$ & $1019(19.7)$ & $812(19.6)$ & & \\
\hline \multicolumn{7}{|c|}{ Maternal education (achievement) } \\
\hline CSE/none & $2447(20.2)$ & & & & - & - \\
\hline \multicolumn{7}{|c|}{ Maternal schooling (y) } \\
\hline $0-4$ & & $1922(33.1)$ & $1441(27.9)$ & $639(15.6)$ & & \\
\hline $5-8$ & & $2425(41.8)$ & $2392(46.4)$ & $1691(41.2)$ & & \\
\hline $9-11$ & & $646(11.1)$ & $911(17.7)$ & $1362(33.2)$ & & \\
\hline$\geq 12$ & & $816(14.1)$ & $417(8.1)$ & $414(10.1)$ & & \\
\hline \multicolumn{7}{|l|}{ Age (y) } \\
\hline$<20$ & $653(4.8)$ & $908(15.6)$ & $910(17.6)$ & $792(19.1)$ & $<0.001$ & - \\
\hline $20-34$ & $11669(85.3)$ & $4339(74.6)$ & $3692(71.5)$ & $2800(67.6)$ & & \\
\hline$\geq 35$ & $1356(9.9)$ & $568(9.8)$ & $565(10.9)$ & $553(13.3)$ & & \\
\hline \multicolumn{7}{|l|}{ Marital status } \\
\hline \multicolumn{7}{|c|}{ Pre-pregnancy body mass index $\left(\mathrm{kg} / \mathrm{m}^{2}\right)$} \\
\hline$<18.5$ & $567(5.0)$ & $384(7.9)$ & $444(8.9)$ & $187(4.9)$ & $<0.001$ & - \\
\hline $18.5-24.9$ & $8387(74.4)$ & $3428(70.1)$ & $3459(68.9)$ & $2342(61.5)$ & & \\
\hline $25.0-29.9$ & $1704(15.1)$ & $867(17.7)$ & $877(17.5)$ & $871(22.9)$ & & \\
\hline$\geq 30$ & $621(5.5)$ & $213(4.4)$ & $239(4.8)$ & $408(10.7)$ & & \\
\hline \multicolumn{7}{|c|}{ Ever smoked during pregnancy } \\
\hline No & $8092(75.9)$ & $3747(64.4)$ & $3453(66.8)$ & $3005(72.5)$ & $<0.001$ & $<0.001$ \\
\hline Yes & $2572(24.1)$ & $2069(35.6)$ & $1715(33.2)$ & $1142(27.5)$ & & \\
\hline \multicolumn{7}{|c|}{ Urinary infection during pregnancy } \\
\hline No & $8689(86.1)$ & NA & $3365(66.5)$ & $2598(62.9)$ & $<0.001$ & - \\
\hline Yes & $1403(13.9)$ & & $1695(33.5)$ & $1535(37.1)$ & & \\
\hline \multicolumn{7}{|c|}{ Hypertension during pregnancy } \\
\hline No & $10658(89.3)$ & NA & $4268(84.3)$ & $3157(76.3)$ & $<0.001$ & - \\
\hline Yes & $1281(10.7)$ & & $793(15.7)$ & $982(23.7)$ & & \\
\hline \multicolumn{7}{|c|}{ Hospital admission during pregnancy } \\
\hline No & $9853(90.4)$ & NA & $4733(91.6)$ & $3694(89.1)$ & $<0.001$ & - \\
\hline Yes & $1044(9.6)$ & & $434(8.4)$ & $453(10.9)$ & & \\
\hline \multicolumn{7}{|c|}{ Delivery attended by a doctor } \\
\hline Yes & $2008(17.7)$ & $3521(60.6)$ & $4505(88.2)$ & $3674(89.1)$ & $<0.001$ & $<0.001$ \\
\hline
\end{tabular}


Table 1 Continued

\begin{tabular}{|c|c|c|c|c|c|c|}
\hline Variables & $\begin{array}{l}\text { ALSPAC 1991/92 } \\
\text { n (\%) }\end{array}$ & $\begin{array}{l}\text { Pelotas } 1982 \\
\text { n (\%) }\end{array}$ & $\begin{array}{l}\text { Pelotas } 1993 \\
\text { n (\%) }\end{array}$ & $\begin{array}{l}\text { Pelotas } 2004 \\
\text { n (\%) }\end{array}$ & $\mathbf{p}^{*}$ & $\mathbf{p} \dagger$ \\
\hline \multicolumn{7}{|l|}{ Type of delivery } \\
\hline Caesarean section & $1157(10.1)$ & $1592(27.4)$ & $1559(30.2)$ & $1856(44.8)$ & & \\
\hline \multicolumn{7}{|c|}{ Intra-uterine growth restriction } \\
\hline \multicolumn{7}{|c|}{ Preterm birth ( $<37$ weeks of gestational age) } \\
\hline No & $12962(94.8)$ & $4330(94.2)$ & $4535(89.1)$ & $3574(86.4)$ & $<0.001$ & $<0.001$ \\
\hline Yes & $716(5.2)$ & $265(5.8)$ & 557 (10.9) & $561(13.6)$ & & \\
\hline
\end{tabular}

multiparae than the ALSPAC study. Urinary infection and hypertension during pregnancy were more prevalent in the 1993 and 2004 Pelotas cohorts than in the ALSPAC study. Deliveries not assisted by a doctor were more prevalent among the ALSPAC women and caesarean sections were more frequent in the Pelotas cohorts.

Over the last two decades trends in maternal and infant's characteristics were demonstrated across the Pelotas cohort studies. An increase in black/mixed ethnic origin women, with extremes in ages, single mothers and an almost twofold increase in pre-pregnancy obesity and caesarean sections were observed. Rates of preterm birth increased by nearly three times in the Pelotas cohorts over time. Negative trends in smoking during pregnancy, deliveries not attended by a doctor and breast feeding for less than 3 months were observed in the Pelotas studies.

In general, for income and education RII and in all birth cohorts, the odds of ever having smoked during pregnancy, delivery non-assisted by a doctor and IUGR were higher in the least advantaged compared to the most advantaged group. (tables 2 and 3). However, the odds of having a caesarean section were lower among the least advantaged compared to those at the top of the income and educational hierarchy. In the 2004 Pelotas cohort study, the poorest women and those with less schooling were more likely to deliver a preterm newborn. No differences in preterm birth were observed in any of the other cohorts. Less-educated women from the ALSPAC and the 2004 Pelotas cohort studies showed higher risk of breast feeding their infants for less than 3 months compared to those with the highest levels of educational attainment. The effect of adjustment for confounders/mediators in most cases reduced the magnitude of SEP-maternal and infant's outcome association without changing its direction.

Higher income-related inequalities were observed for ever smoked during pregnancy in the ALSPAC study than in the Pelotas cohorts (table 4). Greater inequalities in caesarean section were observed in the three Pelotas cohorts than in the ALSPAC study. Higher education-related inequalities in preterm birth were observed in the 2004 Pelotas cohort than in the ALSPAC study. Education had a much more marked effect on breast feeding than income in ASPAC study. While there were no income-related inequalities in breast feeding in the 1982 and
1993 Pelotas cohort studies, the magnitude of education-related inequalities in breast feeding for less than 3 months was almost three times higher in the ALSPAC than in the 2004 Pelotas cohort study.

Trends of stronger education-related inequalities over time were observed in the Pelotas cohorts for smoking during pregnancy, preterm birth and breast feeding for less than 3 months. Decreasing trends in income-related inequalities for IUGR as well as decreasing trends in both income and education-related inequalities for deliveries not attended by a doctor were observed in the Pelotas cohort studies.

\section{DISCUSSION}

In general, in both the UK based and all of the Brazil based birth cohorts, mothers and infants from poorer and less-educated backgrounds had more adverse health outcomes than those from richer and better-educated background. The magnitudes of income and education-related inequalities were outcome and setting specific and were assessed using the RII-a ratio-type measure. Stronger income-related inequalities for smoking and education-related inequalities for breast feeding were observed in the ALSPAC than in the Pelotas cohorts. However, stronger income and education-related inequalities in caesarean section and higher education-related inequalities in preterm birth were observed in the Pelotas cohorts than in the ALSPAC study. Education-related inequalities became wider over time (ie, stronger in more contemporary birth cohorts) in the Pelotas cohorts for smoking, preterm birth and breast feeding.

The main strengths of the study derived from the use of prospective information obtained among large unselected populations with a high response rate and the availability of comparable variables between ALSPAC and the Pelotas cohort studies. However, some methodological difficulties need to be discussed. First, SEP is a complex phenomenon and different indicators have been described to capture its dimensions. Education and occupation, household income and household conditions are frequently used SEP indicators, each reflecting somewhat different individual and societal forces associated with health and disease. In our study, only maternal education and family income were available both in the ALSPAC and the Pelotas cohort studies databases, and it was not possible to 
于 $\bar{\infty}=\overline{0}$

สุํํำ ต

สุ สิ ติ ติ

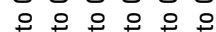

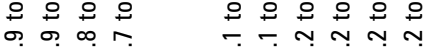

ம் மำ

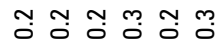

ঢ্ৰ 앙ㅇㅇㅇㅇㅇ $=\stackrel{0}{=} 0.0000$ $==E==00$

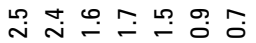
요의 ำ

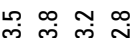

ติ ติ ติ

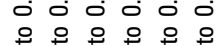

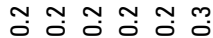

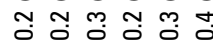

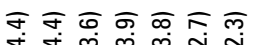

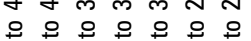
m $\stackrel{m}{\infty} \stackrel{\infty}{=} \stackrel{m}{=}=$ ก

$\bar{x} \bar{x} \bar{x}$ t. $=\infty$ o

क क क़

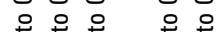

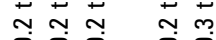
党

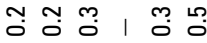

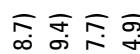
ㅇㅇㅇㅇ

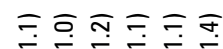

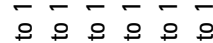
సู 市

শิ

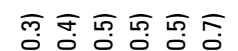
용ㅇㅇㅇㅇ

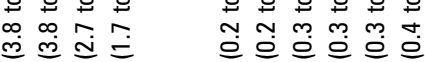
字守

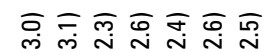
ㅇㅇㅇㅇㅇㅇㅇㅇ

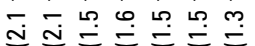

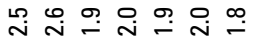

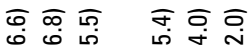
요 0 요

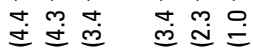

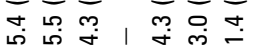

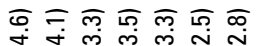
용ㅇㅇㅇㅇㅇ

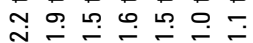

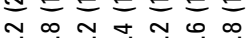
i

कु N $N$ 웅ㅇ

ল ল ㅇㅇㅇㅇㅇ

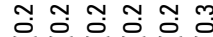
$=\stackrel{\infty}{=}=$

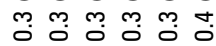

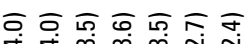
ㅇㅇㅇㅇㅇ 고ำ $\stackrel{\infty}{=} \stackrel{\infty}{=} \stackrel{m}{=}$ 잉 원

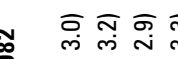
ㅇㅇㅇㅇ $\overline{\mathrm{N}} \overline{\mathrm{N}} \stackrel{\infty}{=} \stackrel{\infty}{=}$

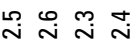

कू 요 우 бㄷำ ก

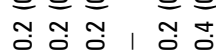

ल

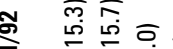

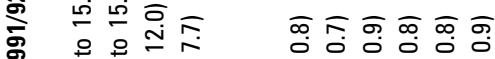

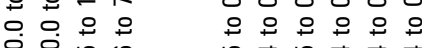

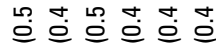
○ 它

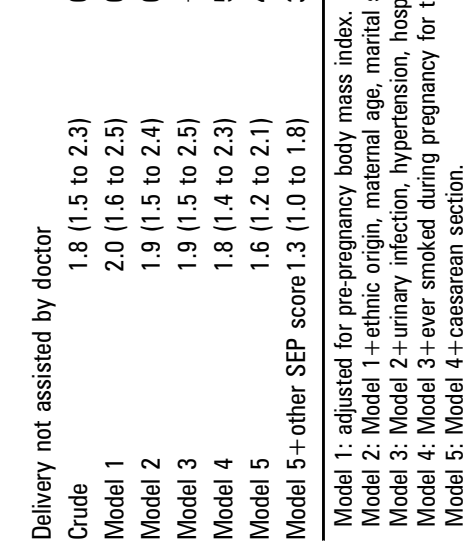


Table 3 Crude and multivariable associations of economic and educational position with infants' outcomes among the ALSPAC and Pelotas birth cohort studies

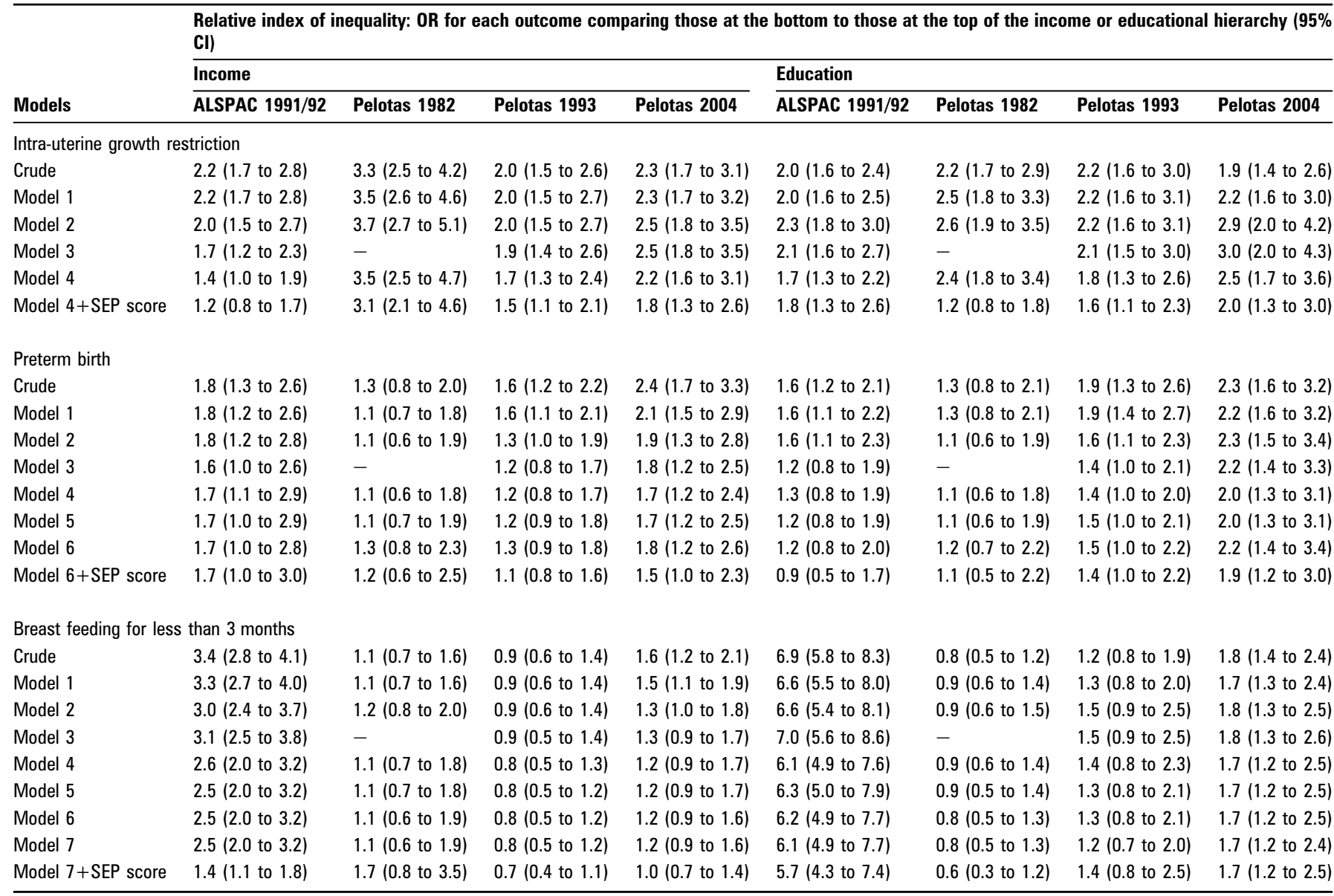

Model 1: adjusted for pre-pregnancy body mass index.

Model 2: Model 1+ethnic origin, maternal age, marital status and parity.

Model 3: Model 2+urinary infection, hypertension, hospital admission during pregnancy.

Model 4: Model 3+ever smoked during pregnancy for the ALSPAC and Pelotas 1993 and 2004; Model 2+ever smoked during pregnancy for the Pelotas 1982 cohort study.

Model 5: Model 4+caesarean section and delivery assisted by doctor.

Model 6: Model 5+intra-uterine growth restriction.

Model 7: Model 6+ preterm birth.

SEP, socioeconomic position.

examine the role of other SEP indicators. Second, maternal education in the Pelotas studies was measured as complete years of schooling while in the ALSPAC study it was measured as educational achievement. Schooling and educational achievement do not mean exactly the same thing. It is possible that stronger education-related inequalities would exist between women who do and do not have higher qualifications. Third, the meaning of family income may vary between settings and may be influenced by family size, but information on the latter was not collected in the perinatal interview for the 1982 Pelotas cohort. Finally, although the proportion of missing values in family income in the ALSPAC database was relatively high, the use of multiple imputation analysis to assess the impact of missing values resulted in effect estimates that were essentially the same as those without imputation, which provides some assurance against substantial selection bias. ${ }^{20}$

We found higher income-related inequalities for smoking during pregnancy in the ALSPAC than in the Pelotas cohort studies. The disadvantages of being poor in a rich and prosperous country compared to being in the same condition in a low or middleincome country have been raised before. ${ }^{21}$ In the Pelotas studies, even though prevalence rates of smoking during pregnancy have declined, inequalities in education-related inequalities are increasing, showing that tobacco control policies and programmes have been reaching the better-educated in a more effective way than the less-educated pregnant women during the last decades.

Patterns of professional attendance at birth varied in the two countries. While midwives deliver over $75 \%$ of UK newborns, in southern Brazil virtually all deliveries are carried out by obstetricians. $^{22}$ This is why deliveries not attended by a doctor are more frequent in the ALSPAC than in Pelotas. Several studies have documented large differences in the use of delivery care according to women's wealth and/or educational levels. ${ }^{23} 24$ In ALSPAC, while low income-related inequalities were found for deliveries not attended by a doctor, education-related inequalities were as high as in the 2004 Pelotas cohort study. Among the Pelotas studies, the largest income-related inequalities were found in the 1982 cohort. Health services could have been inaccessible or unaffordable to women with few economic resources in 1982. The substantial expansion of healthcare services during the early 1990s, as well as an increase in the availability of trained professionals, could explain why trends in both income and education-related inequalities decreased in Pelotas cohort studies throughout the last decades.

Despite continuing debate on the appropriate level of population-based caesarean rates, rates of no less than $5 \%$ and no 

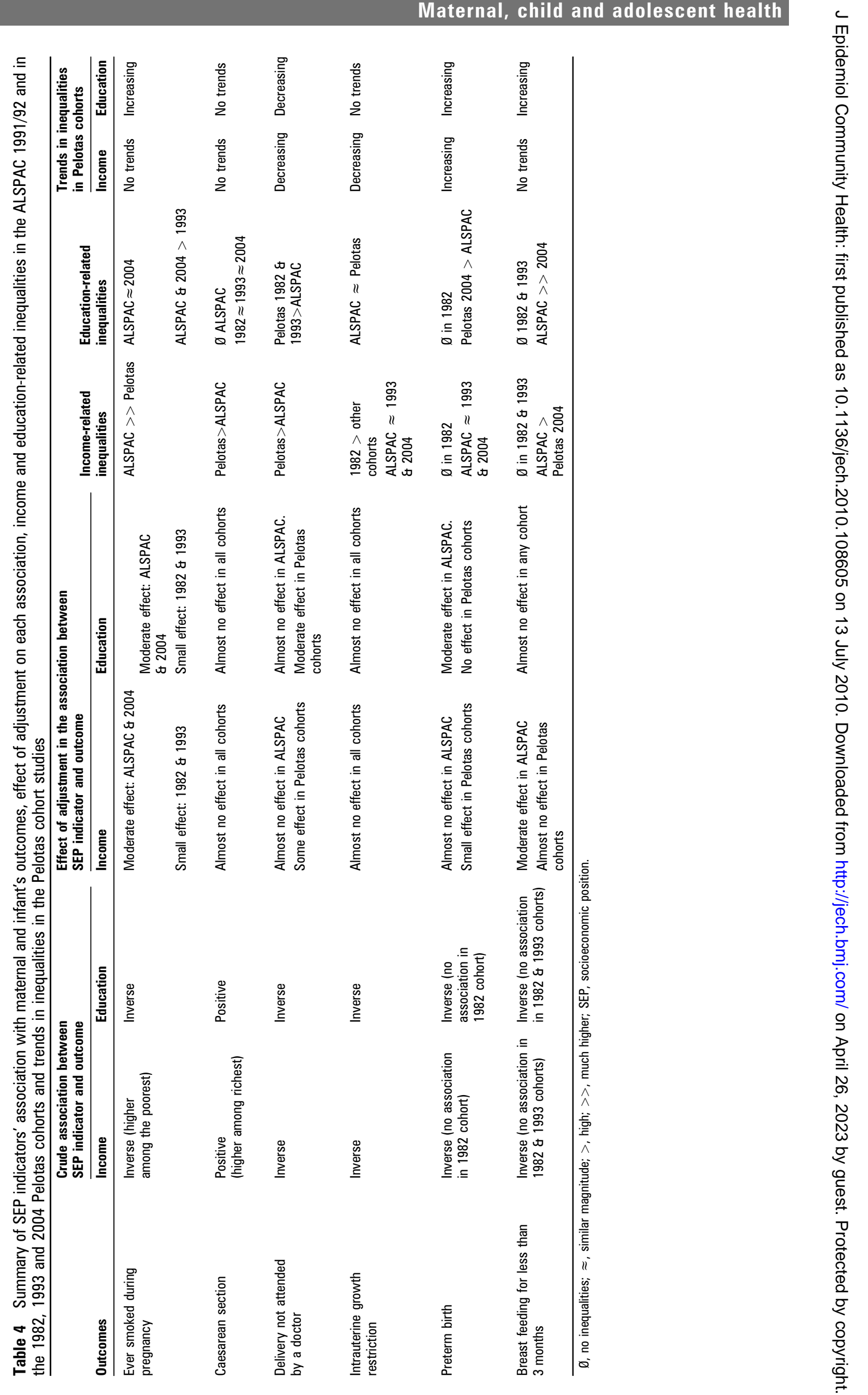
more than $15 \%$ have been recommended. ${ }^{25}$ In the ALSPAC study, the prevalence of caesarean sections was below the recommended upper limit ${ }^{25}$ and no educational-related inequalities were found. In the Pelotas studies, rates of caesarean section were high both in the public and private sector. For private patients, the current rate in Pelotas is at the striking level of $82 \%{ }^{26}$ These differences likely reflect the fact that obstetricians carry out most deliveries in Pelotas, whereas midwives do so in the UK. Higher caesarean sections rates do not mean better quality healthcare and, paradoxically, at least in terms of caesarean section rates, the Latin-American poor may be receiving healthcare of better quality than the rich. ${ }^{27}$ However, targets for this indicator should be determined to assure that those most in need are served and that overuse without health need is actively discouraged.

Poor intrauterine growth and preterm birth are not only predictors for perinatal and neonatal mortality and morbidity but also determine human susceptibility to disease and quality of life later on. ${ }^{28}$ The risk of delivering an IUGR infant was higher among poor and less-educated women, as has been described in previous studies, ${ }^{29}{ }^{30}$ and the magnitude of income and education-inequalities was similar in the ALSPAC and the Pelotas studies. Rates of preterm births, which were almost the same in the ALSPAC and the 1982 Pelotas study, increased in the Pelotas cohorts nearly three-times during the studied perioda finding that was reported in a previous publication. ${ }^{26}$ Neither income nor education-related inequalities were observed in the 1982 Pelotas cohort. In the 2004 Pelotas cohort, educationrelated inequalities in preterm birth become more evident and higher than in the ALSPAC study even after adjustment for maternal and newborn characteristics. These findings are in accordance with other investigations that showed the importance of maternal educational level among other SEP measures as a strong predictor of inequalities in preterm birth. ${ }^{31}$

Breast feeding is the best way of feeding an infant and provides well-known benefits to the infant and the mother. ${ }^{32} 33$ Income-related inequalities in breast feeding were observed in the ALSPAC study but not in the 1982 and 1993 Pelotas cohort studies. High education-related inequalities were found in the ALSPAC study, with magnitudes almost three-times higher than in the 2004 Pelotas cohort study. Our findings are consistent with previously reported observations of substantial inequalities in breast feeding practices within UK. ${ }^{34}{ }^{35}$ Brazil has, for more than $20 \mathrm{y}$, implemented several strategies to promote breast feeding ${ }^{36} 37$ and, specifically, the city of Pelotas was a participating centre in the Multicenter Growth Reference Study (MGRS) where a breast feeding support programme was implemented from 1997-1998. After the MGRS, several interventions promoting breast feeding continued to be carried out in the city, which may underlie increasing trends in breast feeding in the last decades. ${ }^{38}$ However, breast feeding interventions and programmes seemed to have better-reached women with higher schooling, widening the gap between women at the bottom and at the top of the educational hierarchy.

Finally, it should be noted that whereas income and education-related inequalities were evident in both populations, the poorest in the UK were in a better situation than those in Pelotas for all studied health indicators with the exception of breast feeding duration.

\section{CONCLUSION}

The present study was able to make comparisons of the scale of health inequalities in maternal and infant outcomes between populations from a high and a middle-income country and also

\section{What is already known on this subject}

The relation between specific socioeconomic position (SEP) indicators and specific health outcomes can vary between countries due to differences in the cultural contexts of the SEP indicators. Comparisons between high and middle or low-income countries could provide useful insights into the causes of health inequalities.

\section{What this study adds}

Our findings showed that socioeconomic inequalities in health are dynamic and vary between countries, over time and between generations within the same country. Investigations using SEP at different points in the life course should be useful in pointing to specific mechanisms to explain the development and maintenance of health inequalities.

to asses how health inequalities change over time. Our findings showed that socioeconomic inequalities in health are dynamic and vary between countries, over time and between generations within the same country. ${ }^{3} 39$ Maternal education and family income reflect different aspects of the SEP construct and were related to health outcomes in different ways among the studied populations, also altering their effect over time. Even though the SEP indicators used in this study have proved very useful in describing and evaluating health inequalities, they provide only a partial view of socioeconomic inequalities in health. Investigations using SEP at different points in the life course should be useful in pointing to specific mechanisms to explain the development and maintenance of health inequalities.

Acknowledgements We are extremely grateful to all the families who took part in the ALSPAC and Pelotas cohort studies, the midwives for their help in recruiting them, and the whole ALSPAC and Pelotas cohort teams, which include interviewers, computer and laboratory technicians, clerical workers, research scientists, volunteers, managers, receptionists and nurses. The UK Medical Research Council, the Wellcome Trust and the University of Bristol currently provide core support for the ALSPAC

Funding The 1982 Pelotas Birth Cohort study was financed by the International Development Research Centre, Canada, and the 1993 study was financed by the European Union and the Fundação de Amparo à Pesquisa do Rio Grande do Sul, Brazil. The 2004 Pelotas birth cohort study was financed by the Division of Child and Adolescent Health and Development of WHO, by the 'Conselho Nacional de Desenvolvimento Científico e Tecnológico', Brazil, and by the 'Pastoral da Criança' (Catholic non-governmental organisation, Curitiba, Brazil).This research was specifically funded by the The Wellcome Trust (Project: 'Socioenomic \& racial/ethnic inequalities in maternal and child health \& healthcare in two populations: the Pelotas birth cohorts (1982, 1993 \& 2004) \& the 1991 ALSPAC cohort', Wellcome Trust grant $\mathrm{N}^{\circ} 082429 / \mathrm{Z} / 07 / \mathrm{Z}$

\section{Competing interests None.}

Ethics approval Ethics approval for the study was obtained from the ALSPAC Law and Ethics Committee and the Local Research Ethics Committees. The study protocol of 1982, 1993 and 2004 Pelotas cohort studies was approved by the Medical Ethics Committee of the Federal University of Pelotas, affiliated with the Brazilian Federal Medical Council.

Contributors AM originated the research question, conducted the analyses and wrote the first dart of the article. CGV, JG, DAL and GDS contributed to the analysis and interpretation of the findings as well as the writing of the article. AMBM, CLA, AJDB, ISS and FCB contributed to the interpretation of the findings and assisted with the editing of the article. 
Provenance and peer review Not commissioned; externally peer reviewed.

\section{REFERENCES}

1. Galobardes B, Shaw M, Lawlor DA, et al. Indicators of socioeconomic position (part 1). J Epidemiol Community Health 2006:60:7-12.

2. Lynch J, Kaplan G. Socioeconomic position. In: Berkman L, Kawachi I, eds. Social epidemiology. Oxford: Oxford University Press 2000:13-35

3. Lawlor DA, Harro M, Wedderkopp N, et al. Association of socioeconomic position with insulin resistance among children from Denmark, Estonia, and Portugal: cross sectional study. BMJ 2005;331:183.

4. Lawlor DA, Tooth $\mathrm{L}$, Lee $\mathrm{C}$, et al. A comparison of the association between socioeconomic position and cardiovascular disease risk factors in three age cohorts of Australian women: findings from the Australian Longitudinal Study on Women's Health. J Public Health (Oxf) 2005:27:378-87.

5. Laaksonen M, Rahkonen 0, Martikainen P, et al. Socioeconomic position and selfrated health: the contribution of childhood socioeconomic circumstances, adult socioeconomic status, and material resources. Am J Public Health 2005;95:1403-9.

6. Davey Smith G, Carroll D, Rankin S, et al. Socioeconomic differentials in mortality: evidence from Glasgow graveyards. BMJ 1992;305:1554-7.

7. Davey Smith G, Hart C, Hole D, et al. Education and occupational social class: which is the more important indicator of mortality risk? J Epidemiol Community Health 1998:52:153-60.

8. Galobardes B, Lynch J, Davey Smith G. Measuring socioeconomic position in health research. Br Med Bull 2007:81-82:21-37.

9. Kramer MS, Wilkins R, Goulet L, et al. Investigating socio-economic disparities in preterm birth: evidence for selective study participation and selection bias. Paediatr Perinat Epidemiol 2009:23:301-9.

10. Spencer $\mathbf{N}$, Law $\mathbf{C}$. Inequalities in pregnancy and early years and the impact across the life course: progress and future challenges. In: Dowler E, Spencer N, eds. Challenging health inequalities. From Acheson to "Choosing health". Bristol: The Policy Press, 2007

11. Golding J, Pembrey M, Jones R. ALSPAC-the Avon longitudinal study of parents and children. I. Study methodology. Paediatr Perinat Epidemiol 2001:15:74-87.

12. Golding J, Team AS. The Avon longitudinal study of parents and children (ALSPAC) - study design and collaborative opportunities. Eur J Endocrinol 2004;151(Suppl 3):U119-23.

13. Barros AJ, Santos IS, Victora CG, et al. The 2004 Pelotas birth cohort: methods and description [in Portuguese]. Rev Saude Publica 2006:40:402-13.

14. Victora CG, Barros FC. Cohort profile: the 1982 Pelotas (Brazil) birth cohort study. Int J Epidemiol 2006;35:237-42.

15. Victora CG, Hallal PC, Araujo CL, et al. Cohort profile: the 1993 Pelotas (Brazil) birth cohort study. Int J Epidemiol 2008;37:704-9.

16. Alexander GR, Himes JH, Kaufman RB, et al. A United States national reference for fetal growth. Obstet Gynecol 1996;87:163-8.

17. Kramer MS, Platt RW, Wen SW, et al. A new and improved population-based Canadian reference for birth weight for gestational age. Pediatrics 2001:108:E35.

18. WHO Consultation on obesity. Obesity: preventing and managing the global epidemic. Geneva: WHO, 1998.
19. Wagstaff A, Paci P, van Doorslaer E. On the measurement of inequalities in health Soc Sci Med 1991;33:545-57.

20. Royston P. Multiple imputation of missing values: update. Stata J 2005:5:188-201.

21. Rainwater L, Smeeding TM. Poor kids in a rich country: America's children in comparative perspective. New York: Russell Sage, 2003

22. Page L. Human resources for maternity care: the present system in Brazil, Japan North America, Western Europe and New Zealand. Int J Gynaecol Obstet 2001;75 (Suppl 1):S81-8

23. Elo IT. Utilization of maternal health-care services in Peru: the role of wo men's education. Health Transit Rev 1992;2:49-69.

24. Raghupathy S. Education and the use of maternal health care in Thailand. Soc Sci Med 1996:43:459-71.

25. Unicef WHO UNFPA. Guidelines for monitoring the availability and use of obstetric services. New York, USA: UNICEF, 1997.

26. Barros FC, Victora CG, Barros AJ, et al. The challenge of reducing neonatal mortality in middle-income countries: findings from three Brazilian birth cohorts in 1982, 1993 and 2004. Lancet 2005;365:847-54.

27. Althabe F, Belizan JM. Caesarean section: the paradox. Lancet 2006;368:1472-3

28. Barker DJ. Fetal origins of coronary heart disease. BMJ 1995;311:171-4.

29. Parker JD, Schoendorf KC, Kiely JL. Associations between measures of socioeconomic status and low birth weight, small for gestational age, and premature delivery in the United States. Ann Epidemiol 1994:4:271-8.

30. Raum E, Arabin B, Schlaud M, et al. The impact of maternal education on intrauterine growth: a comparison of former West and East Germany. Int J Epidemio 2001;30:81-7

31. Morgen CS, Bjork C, Andersen PK, et al. Socioeconomic position and the risk of preterm birth - a study within the Danish National Birth Cohort. Int J Epidemiol 2008:37:1109-20.

32. Quinn PJ, O'Callaghan M, Williams GM, et al. The effect of breastfeeding on child development at 5 years: a cohort study. J Paediatr Child Health 2001:37:465-9.

33. Singhal A, Cole TJ, Lucas A. Early nutrition in preterm infants and later blood pressure: two cohorts after randomised trials. Lancet 2001;357:413-19.

34. Griffiths LJ, Tate AR, Dezateux $C$. The contribution of parental and community ethnicity to breastfeeding practices: evidence from the Millennium Cohort Study. Int J Epidemiol 2005;34:1378-86.

35. Griffiths LJ, Tate AR, Dezateux C. Do early infant feeding practices vary by maternal ethnic group? Public Health Nutr 2007;10:957-64.

36. Brady Sde 0. Protecting breastfeeding: Brazil's story. Pract Midwife 2003;6:14-16.

37. Rea MF. [A review of breastfeeding in Brazil and how the country has reached ten months' breastfeeding duration]. (In Portuguese). Cad Saude Publica 2003;19(Supp 1): $\$ 37-45$

38. Albernaz $\mathbf{E}$, Araujo CL, Tomasi $\mathrm{E}$, et al. Influence of breastfeeding support on the tendencies of breastfeeding rates in the city of Pelotas, RS, Brazil, from 1982 to 2004. J Pediatr (Rio J) 2008;84:560-4.

39. Davey Smith G, Lynch J. Life course approaches to socioeconomic differentials in health. In: Kuh D, Ben-Shlomo Y eds. A life course approach to chronic disease epidemiology. Oxford: Oxford University Press, 2004:77-115. 